\title{
A Ricardian Model of New Trade and Location Theory
}

\author{
Luca Antonio Ricci \\ International Monetary Fund
}

\begin{abstract}
This paper provides a new model of firm's location choices. It integrates a Ricardian model of comparative advantage with the location effects deriving from trade costs, increasing returns to scale, product differentiation, and monopolistic competition. In a two-region, two-differentiated-good, one-factor framework, the regional degree of specialization depends positively on the extent of the comparative advantage in productivity and on the degree of returns to scale; it depends negatively on the magnitude of the trade costs. Hence, the model accommodates high levels of intra-industry trade among

* Correspondence Address: IM F - Research Department, Washington D.C., 20431, U.S.A.; Tel: (202) 623 6007; Fax: -6334, LRICCI@IM F.ORG; This paper draws on a chapter of my PhD thesis at the Graduate Institute of International Studies (GIIS). Previous drafts have been written while I was Visiting F ellow at the Department of Economics of Harvard University; it has been completed while I was at the University of Konstanz under the HCM program. I am grateful to my thesis advisors Richard Baldwin and Hans Genberg and to Donald Davis, Federico Trionfetti, and Jaume Ventura for helpful comments. I thank all the participants in the Harvard International Economics Workshop, in a seminar at the University of Rome "La Sapienza", and in the IInd meeting (LSE-CEP, London) of the ESF -funded Research Group on 'E uropean Economic Performance'. Generous financial support from the Swiss National Research F unds is gratefully acknowledged. I am the only responsible for any error. The ideas presented in the paper are those of the author and do not necessarily reflect those of the IM F.
\end{abstract}

(C1997 - Institute for International Economics, Sejong Institution. All rights reserved. 
countries with similar level of development, as well as high levels of interindustry trade among countries with different technologies. (JEL Classifica tion: F11, F12, F15, L13, R12)

\section{Introduction}

This paper contributes to bridging the gap between traditional trade theory and recent trade and location theory, by combining a Ricardian comparative advantage with the key elements of new trade and location theory. Full specialization and pure inter-industry trade ${ }^{1}$ typical predictions of a standard Ricardian model, characterize one of the two possible equilibria of the model. In the other equilibrium, countries are relatively specialized and engage in both inter-and intra industry trade. The degree of specialization depends positively on the comparative advantage and on the degree of returns to scale, and negatively on the trade costs.

Traditional trade theory emphasizes the comparative advantage as a source of trade. In the presence of homogenous goods, constant returns to scale, and perfect competition, countries trade when they are relatively different in technologies (Ricardo), in factor endowments (Heckscher-Ohlin), or, less important, in preferences. In absence of these differences, there is no scope for trade.

During the last two decades, a great deal of emphasis has been put on the source of trade deriving from increasing returns to scale, product differentiation, and monopolistic competition /see for example Krugman [1990], and Helpman and Krugman [1985] $\rangle$. Under such assumptions, every firm has an incentive to concentrate its production in one plant and to manufacture a different variety than its competitors; hence, countries are naturally specialized in the production of different varieties. Because all varieties are demanded

1. We distinguish intra-industry versus inter-industry trade according to the (respectively high versus low) substitutability of tradables in consumption. The distinction between intra-industry and inter-industry based on the similarity of factor intensities of tradables is not of interest in a one-factor model (as the Ricardian model): because there is only one possible factor intensity, all trade would be by definition intra-industry trade, independently of whether it is meant to represent, for example, trade in different types of cars or trade of cars versus food. 
as imperfect substitutes by all consumers, gains from trade arise even in the absence of a comparative advantage.

M ore recently, Krugman [1991] has focused on the interesting location effects that arise once we add trade costs ${ }^{2}$ and partial factor mobility ${ }^{3}$ to the set of assumptions characterizing recent trade theory and listed above. Since then, this 'economic geography approach' has stimulated a vast and varied literature on the location choices of firms.

Efforts to integrate traditional trade theory with the recent trade and location theory have been successful but mainly limited ${ }^{4}$ to the HeckscherOhlin idea of comparative advantage based on factor endowments. In Helpman and K rugman [1985, ch.7], both inter- and intra-industry trade occur in an Heckscher-Ohlin world where one sector is characterized by product differentiation, monopolistic competition, and increasing returns to scale. $\mathrm{M}$ artin and Rogers [1995] adapt such framework, by introducing capital mobility and country specific transport costs, to investigate the effects of public infrastructure on industrial location and therefore on regional development.

Differences in comparative production costs across countries, à la Ricardo, have not yet been combined with recent trade and location theory. In order to fill such a gap, we propose a very simple and didactic framework. A Ricardian comparative advantage is assumed to arise in a two-region ${ }^{5}$ twogood one-factor world characterized by increasing returns to scale, product differentiation, monopolistic competition, trade costs, and factor immobility (across locations). We find closed form solutions for the number of varieties of each good produced in each location ${ }^{6}$ and therefore for the degree of specialization. The degree of specialization rises with the extent of the comparative advantage and of the returns to scale, and diminishes with trade costs.

2. Trade costs must be broadly interpreted: the cost for a firm of serving different locations may depend on transport costs, tariffs and other protectionist measures, cultural and lingual differences, and so on.

3. This assumption is not crucial. See for example Krugman and Venables [1996].

4. See however Krugman [1980] for an analysis of asymmetric preferences across countries within the recent trade theoretical approach.

5. We use indifferently the words regions and locations; they can also be thought of as countries.

6. Such close form solutions are unusual in location models. 
Interestingly, for some parameter values, regions are fully specialized, as in a standard Ricardian model, and engage in inter-industry trade only. For other parameter values, both locations are relatively specialized in the good in which they have a comparative advantage, and engage in both inter-and intra-industry trade.

In a standard Ricardian model countries are normally fully specialized ${ }^{7}$ and engage in inter-industry trade only. For such features, the model has been criticized as unable to explain the large trade flows among similar countries 〈Krugman Obstfeld [1991], p. 29; Helpman [1987], p. 63〉. Those features however, must not necessarily be associated with a Ricardian comparative advantage.

Our contribution shows indeed that not only factor proportions theory 〈as in Helpman Krugman [1985]) but also a Ricardian comparative advantage, when combined with new trade and location theory, can generate partial specialization and induce intra-industry as well as inter-industry trade. Depending on parameter values, the degree of specialization ranges from identical countries to full specialization, accompanied by changes in the ratio of inter-industry to intra-industry trade. The model can ther efore natu rally accommodate high levels of trade (mostly intra-industry trade) among countries with similar level of development, as well as high levels of trade ( mostly inter-industry trade) among countries with different technologies.

Within the traditional trade theor $y$, partial specialization of both countries in a Ricardian framework has been derived by adding a comparative advantage of the Heckscher-Ohlin type 〈Woodland [1982], p. 187-190〉 or by interpreting the Ricardian approach as a special Heckscher-Ohlin framework where the technological comparative advantage is a property of perfectly substitutable factors of production rather than of countries 〈Ruffin [1988]〉. Davis [1995] shows both inter-and intra-industry trade ${ }^{8}$ can occur in a model combining Ricardo and Heckscher-O hlin.

The Ricardian comparative advantage seems to be much more powerful than the standard Ricardian model shows. It is just necessary to bear in

7. The limiting case of one country not fully specialized occurs when international relative prices are equal to the autarky prices of this country.

8. $\mathrm{H}$ is analysis adopts the distinction between inter- and intra-industry trade based on the similarity of factor content (see footnote 1 ). 
mind that more than one source of trade is likely to be springing at the same time.

The intuition of our framework is as follows. Assume that each location is more efficient in the production of one good. In the absence of trade costs, the comparative (and absolute) advantage would generate full specialization, as in a standard Ricardian model. In fact, increasing returns to scale at firm level and product differentiation would induce every firm producing one variety to locate in only one place. The choice of the location would be based only on the productivities, as no other location effect is at work.

However, the presence of trade costs creates a segmentation of the two markets. Trade costs alter the relative price of two varieties of the same good produced in different locations. The consequent substitution effect induces every consumer to demand more of the variety produced in his/ her location. Such an effect will grow stronger as the elasticity of substitution across varieties becomes larger.

As a consequence, if the gap in productivity is not very high, while trade costs are high enough, the location which has a comparative di sadvantage in the production of a given good accommodates nonetheless some firms producing varieties of such good. In fact, these firms face higher costs of production, but the better access to serve the local market allows them to charge a higher price. ${ }^{9}$ They can therefore reach the same level of profits as their competitors located in the more productive area.

It is also possible, however, that the location effect arising from the comparative advantage is strong enough to dominate the dispersion effect induced by trade costs, thereby generating full specialization.

The next section describes the model. Section III presents the equilibrium location distribution. Section IV draws conclusions. As the problem is fairly complex, we adopt some special assumptions in order to convey intuition and results within a simple framework. Labor is both immobile and equally distributed across the two locations. The shares of expenditure on good $A$ and $B$ are equal. The comparative advantage is specular across loca-

9. It is important to note that the share of varieties of one good produced in one location is not associated with the market size of that location /contrary to the core-periphery model, Krugman [1991] $\rangle$. In fact, a mirror-image sectoral structure ensures that the two regions have equal size. 
tion. This set of assumptions ensures that the two regions have a mirrorimage structure. We will discuss in section IV the consequences of relaxing such assumptions.

\section{The Model}

Consider a world constituted by two locations ( 1 and 2) which are inhabited by the same amount of individuals $(L)$. There is only one factor of production (labor, $L$ ) which is immobile across locations and mobile across sectors.

\section{A. Preferences and Endowments}

All individuals share the same utility function. A representative consumer ${ }^{10}$ of region $k(k=1,2)$ chooses consumption of varieties of good $A$ and $B\left(c_{i A k}\right.$ and $c_{j B k}$ respectively) so as to maximize the following preferences:

$$
\mathrm{U}_{\mathrm{k}}=\left(\mathrm{C}_{\mathrm{Ak}} \mathrm{C}_{\mathrm{Bk}}^{1-}\right)
$$

with

$$
C_{A K}=\left(\sum_{i=1}^{n_{A}} c_{i A k}^{(-1) /}\right)^{\prime(-1)}, C_{B K}=\left(\sum_{j=1}^{n_{B}} c_{j B k}^{(-1) /}\right)^{\prime \prime-1)}, \quad>1
$$

where $\sigma$ is the elasticity of substitution among varieties of the same good, and $\gamma$ is set for convenience to .5. $n_{A}$ and $n_{B}$ are the number of varieties of goods and $A$ and $B$ effectively produced. Every individual supplies inelastically one unit of labor to domestic firms at the current domestic wage $\left(w_{k}\right)$, and receives profits ( $\pi_{k}=0$ in equilibrium) from these firms. There are no assets. The consumer' $s$ budget constraint is:

$$
\sum_{i=1}^{n} p_{i A}^{k} c_{i A k}+\sum_{j=1}^{n} p_{j B}^{k} c_{j B k}=w_{k}+k
$$

where $p_{i A}^{k}$ and $p_{j B}^{k}$ are the prices of variety $i$ of good $A$ and of variety $j$ of good

10. As agents of different locations may face different prices, we need to distinguish them. 
$B$ as perceived by the consumers of location $k$. Such prices (when related to varieties produced in the other region) differ from the producer prices because of trade costs incurred by consumers. Symmetric trade costs $(\tau)$ are of the Samuelson's iceberg type. ${ }^{11}$

As we will focus only on the equilibrium property of the model, in order to simplify the exposition we make the informed guess that the nominal wage is equal in the two regions ( $w$ ); this would be true in equilibrium, as proven in the appendix.

\section{B. Technology and Comparative Advantage ${ }^{12}$}

Each good can be produced in a large number of varieties; the number of varieties actually produced is determined endogenously. Each variety is manufactured by a different firm. Increasing returns to scale arise from the presence of fixed costs and constant marginal costs, both in terms of labor. The fixed costs are identical for all sectors and for all locations $(\alpha)$. The marginal labor requirement for all varieties of $A$ produced in 1 and for all varieties of $B$ produced in 2 is the same $(\beta)$. Similarly, the marginal labor requirement for all varieties of $A$ produced in 2 and for all varieties of $B$ produced in 1 is the same $\left(\beta^{\prime}\right)$. Formally:

$$
\begin{aligned}
& I_{A i 1}=\alpha+\beta x_{A i 1} ; I_{B j 1}=\alpha+\beta^{\prime} x_{B j 1} \\
& I_{A i 2}=\alpha+\beta^{\prime} x_{A i 2} ; \quad I_{B j 2}=\alpha+\beta x_{B j 2} \quad \text { with } \beta^{\prime}>\beta
\end{aligned}
$$

where $I_{A i 1}$ is the labor required to produce $x_{A i 1}$ units of variety $i$ of good $A$ in location 1 ; similarly for the other labels. The inequalities $\beta^{\prime}>\beta$ ensures that region 1 (2) has a comparative advantage ${ }^{13}$ in good $A$ ( $B$ ). The parameter $\delta=\beta^{\prime} / \beta$ measures the extent of the comparative advantage.

11. As in most trade models, iceberg trade costs are assumed because of convenience: in particular, they do not affect the marginal cost of selling to a foreign market.

12. Relative differences in productivities in the Ricardian framework are commonly attributed to technological differences. One could also conceive, however, that sectors within each location are differently affected by domestic institutions, industrial policies, infrastructure, and so on.

13. This specification delivers not only a comparative but also an "absolute" advantage for each location. 


\section{Firms' Behavior}

The market structure is the usual large group monopolistic competition $\langle$ Dixit Stiglitz [1977] $\rangle$. All firms 'fk' producing varieties of good $f(f=A, B)$ in location $k(k=1,2)$ face always the same situation and we do not need to distinguish among them. ${ }^{14}$ Firms profit maximization implies the usual markup pricing:

$$
p_{A 1}=p_{B 2}=\frac{}{-1} w ; \quad p_{A 2}=p_{B 1}=' \frac{}{-1} w
$$

hence

$$
\frac{P_{A 1}}{P_{A 2}}=\frac{P_{B 2}}{P_{B 1}}=-1=\frac{1}{1}
$$

where $p_{\mathrm{fk}}$ is the producer price of one variety of good $\mathrm{f}$ manufactured in location $\mathrm{k}$.

The zero profit condition due to monopolistic competition delivers the following optimal outputs $x_{f k}$ for a firm producing one variety of $f$ in $k$ :

$$
\left.\mathrm{x}_{\mathrm{A} 1}=\mathrm{x}_{\mathrm{B} 2}=-(-1) ; \mathrm{X}_{\mathrm{B} 1}=\mathrm{x}_{\mathrm{A} 2}=-1-1\right)
$$

Therefore, ${ }^{15}$ within a sector ( $A$ or $B$ ), each firm located in the region which is less advantageous for that sector finds it optimal to charge a higher price and to produce a smaller output that a competitor located in the other region. However, all firms share the same optimal employment $\left(\mathrm{l}_{\mathrm{fk}}\right)$ and sales $\left(p_{\mathrm{fk}} x_{\mathrm{fk}}\right)$, as one can easily derive from the previous conditions:

$$
\mathrm{I}_{\mathrm{fk}}=\alpha \sigma=\mathrm{I} \quad \forall \mathrm{f}=\mathrm{A}, \mathrm{B} \quad \mathrm{k}=1,2
$$

14. The introduction of different productivities 'across markets' within the same sector (in order to allow for the comparative advantage) does not alter the usual market structure: in particular, all firms located in the same region still face the same demand function and choose the same optimal prices and output.

15. Note that the formulas for prices and output are very similar to those in standard new trade theory models without productivity differentials; in particular, optimal choices of each firm do not depend on other firms' productivity nor on the number of firms in each market. As usual in new trade theory, in fact, the perceived elasticity of demand is constant and every firm takes for given other firms' behavior. The firm's profit-maximizing price is then independent of other firm's productivity and of the number of firms, and so are the zero-profit outputs consistent with those prices. 


$$
p_{\mathrm{fk}} \mathrm{X}_{\mathrm{fk}}=\mathrm{W} \alpha \sigma=\mathrm{s} \quad \forall \mathrm{f}=\mathrm{A}, \mathrm{B} \quad \mathrm{k}=1,2
$$

where I and s are, respectively, the common level of optimal employment and sales. Therefore, the number of varieties of good f produced in location $\mathrm{k}\left(\mathrm{n}_{\mathrm{fk}}\right)$ is proportional to the labor devoted to the production of $f$ in $k\left(\mathrm{~L}_{\mathrm{fk}}\right)$ :

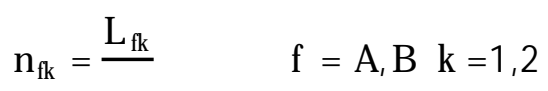

\section{Consumers' Behavior}

The solution to the consumers maximization problem implies that every individual will allocate an equal share of expenditure on each good. As all consumers of one location face the same prices and have homothetic utility functions, we can derive the aggregate demands of region $\mathrm{k}$ for each variety of good $A$ produced in region $k^{\prime}$ ( $A_{k^{\prime}}^{k}$; superscripts $k$ indicate the location of the consumers, while subscripts $k^{\prime}$ denote the location where the variety is produced):

$$
\begin{aligned}
& A_{1}^{1}=\frac{p_{A 1}^{-}}{n_{A 1} p_{A 1}^{1-}+n_{A 2}\left(p_{A 2}\right)^{1-}} w L \quad ; \quad A_{2}^{1}=\frac{\left(p_{A 2}\right)^{-}}{n_{A 1} p_{A 1}^{1-}+n_{A 2}\left(p_{A 2}\right)^{1-}} w L \\
& A_{1}^{2}=\frac{\left(p_{A 1}\right)^{-}}{n_{A 1}\left(p_{A 1}\right)^{1-}+n_{A 2} p_{A 2}^{1-}} w L \quad ; \quad A_{2}^{2}=\frac{p_{A 2}^{-}}{n_{A 1}\left(p_{A 1}\right)^{1-}+n_{A 2} p_{A 2}^{1-}} w L
\end{aligned}
$$

where, under the common assumption that $n_{A}$ is large, $\sigma$ approximates the perceived elasticity of demand. The expressions for good $B\left(B_{k}^{k}\right)$ can be derived analogously.

\section{The Equilibrium Location Structure}

The difference in productivities provides an incentive for firms producing A to locate in region 1 and vice versa for firms producing B. B ut will specialization be full? Will some firms locate in the region which is less advantageous for their production? If so, to what extent and why? These are the questions we address in this paragraph.

In equilibrium, demand for each variety equals its supply:

$$
x_{\mathrm{fk}}^{d}=x_{\mathrm{fk}} \quad \forall f=A, B \quad k=1,2
$$

where

$$
X_{A k}^{d}=A_{k}^{1}+A_{k}^{2} \quad X_{B k}^{d}=B_{k}^{1}+B_{k}^{2}
$$

Therefore, in equilibrium expenditure allocations on all varieties are identical: ${ }^{16}$

$$
p_{\mathrm{fk}} \mathrm{x}_{\mathrm{fk}}^{\mathrm{d}}=\mathrm{s} \quad \forall \mathrm{f}=\mathrm{A}, \mathrm{B} \quad \mathrm{k}=1,2
$$

As each location is endowed with an amount of labor equal to $L$, full employment requires that: 


$$
L_{A 1}+L_{B 1}=L=L_{A 2}+L_{B 2} \text { hence } n_{A 1}+n_{B 1}=n_{A 2}+n_{B 2}
$$

while utility maximization and goods market equilibrium imply that:

$$
\mathrm{n}_{\mathrm{A}}=\mathrm{n}_{\mathrm{B}}=\mathrm{n}, \quad \mathrm{n}_{\mathrm{A} 1}+\mathrm{n}_{\mathrm{A} 2}=\mathrm{n}_{\mathrm{B} 1}+\mathrm{n}_{\mathrm{B} 2}
$$

where $\mathrm{n}$ is the total number of varieties of each good. These two conditions make sure that the two regions have a mirror-image production structure:

$$
\mathrm{n}_{\mathrm{A} 1}=\mathrm{n}_{\mathrm{B} 2}, \quad \mathrm{n}_{\mathrm{A} 2}=\mathrm{n}_{\mathrm{B} 1}
$$

We then need to determine just one of the four $\mathrm{n}_{\mathrm{fk}}$, and the other numbers of varieties $\left(\mathrm{n}_{\mathrm{fk}}\right)$ and employment levels $\left(\mathrm{L}_{\mathrm{fk}}\right)$ will follow automatically.

The symmetry of our model implies that the goods market equilibrium conditions for good A are exactly the same as those for good B. By Walras Law, we are left with one independent goods market equilibrium condition. By equating (say) demand and supply of one variety of good A produced in location 1:

$$
\frac{p_{A 1}^{1-} w L}{n_{A 1} p_{A 1}^{1-}+n_{A 2}\left(p_{A 2}\right)^{1-}}+\frac{\left(p_{A 1}\right)^{1-} w L}{n_{A 1}\left(p_{A 1}\right)^{1-}+n_{A 2} p_{A 2}^{1-}}=w
$$

and substituting for the profit maximizing prices, we derive a closed-form solution for the share of the varieties of each good produced in each location:

$$
\begin{aligned}
& \mathrm{h}=\frac{\mathrm{n}_{\mathrm{A} 1}}{\mathrm{n}}=\frac{\mathrm{n}_{\mathrm{B} 2}}{\mathrm{n}}=\frac{1}{2}+\frac{-1\left(^{2(-1)}-1\right)}{2\left[{ }^{-1}\left(1+^{2(-1)}\right)-{ }^{-1}\left(1+{ }^{2(-1)}\right)\right.}, \\
& 1-\mathrm{h}=\frac{\mathrm{n}_{\mathrm{A} 2}}{\mathrm{n}}=\frac{\mathrm{n}_{\mathrm{B} 1}}{\mathrm{n}}
\end{aligned}
$$

$\mathrm{h}(.5<\mathrm{h}<1)$ being an index of regional specialization or of sectoral concentration in each location.

The degree of specialization (h) increases with the difference in productivity across locations for the same sector $(\delta)$, and with the degree of returns to scale (which is inversely related to the elasticity of substitution between varieties, $\sigma)$, and decreases with the level of trade costs $(\tau)$. An $h$

16. We in fact know that optimal sales are identical for all firms (from profit maximization and monopolistic competition) 
close to .5 indicates that the two regions have a very similar production structure, while an $\mathrm{h}$ close to 1 corresponds to a very large degree of specialization or of sectoral concentration. $\mathrm{h}$ never lies between 0 and .5, as locations would be specializing in the good for which they are least productive. A value of $h$ which is negative or above 1 indicates that locations are fully specialized in the good in which they have a comparative advantage.

The rationale is simple. Because of internal economies of scale, each firm chooses to locate in only one region. Concentration of one sector in one region is promoted by the incentive to exploit the productivity advantage of that region. Dispersion of the same sector across locations is pushed by the competition of firms for segmented markets, as trade costs create a price wedge between prices of different locations and the substitution effect translates this wedge into higher demand for local goods.

T wo types of equilibria may arise. In the first scenario, full specialization, as in a standard Ricardian model, occurs when a large productivity gap for the same sector across different locations is coupled with low trade costs and large increasing returns to scale. All firms producing the same good locate in the region which has a comparative advantage in that good, as in the other region they would obtain lower sales and profits.

Regions become relatively (and no more completely) specialized if the comparative advantage becomes smaller: in the presence of a small productivity gap, even small trade costs are enough to induce some degree of industrial dispersion. The same is true for higher trade costs, or smaller increasing returns to scale. The equilibrium distribution of firms is reached when all firms (independently of their location and production) face the same sales and the same profits.

As expected, the equilibrium is stable. ${ }^{17}$ If some firms producing good $A$ in 1 relocated in region 2 , the expenditure on one variety of good A produced in 2 would decrease relatively to the expenditure on a competing variety from region 1 : 


$$
\begin{aligned}
& \left.\frac{\left(p_{A 2} x_{A 2}^{d}-p_{A 1} x_{A 1}^{d}\right)}{n_{A 2}}\right|_{\left\{n_{A 1}=-d n_{A 2} \cdot \frac{n_{A 1}}{n_{A}}=h\right\}} \\
& =-\frac{\left.g-1+(/)^{-1}\right]^{2}\left[-1+()^{-1}\right]^{2}}{\left[-(/)^{-1}+()^{-1}\right]^{2}\left(n_{A}\right)^{2}}<0
\end{aligned}
$$

Within sector $A$, profits would then be higher in region 1 , generating an incentive to relocate in this region, until the equilibrium distribution of firms is restored.

\section{Conclusions}

This paper contributes to the analysis of how different sectors tend to concentrate or spread across locations and therefore how regions specialize or develop a similar production structure. We introduce a Ricardian comparative advantage, based on relative differences in productivities across locations, with a recent trade and location approach, based on increasing returns to scale, trade costs, monopolistic competition, and product differentiation.

Depending on the parameters of the model, the degree of specialization of countries can vary from identical production structure to full specialization. The extent of trade in varieties of the same good versus trade in varieties of different goods varies jointly with the degree of specialization. The model can thus naturally describe both high levels of intra-industry trade among countries with similar level of development and high levels of interindustry trade among countries with different technologies.

Internal economies of scale induce each firm to locate in only one region. Concentration of one sector in one location is induced by the incentive to exploit the productivity advantage of that location. Dispersion of the same sector across locations is pushed by the competition of firms for segmented markets, as trade costs create a price wedge between prices of different locations and the substitution effect translates this wedge into a higher

17. Given the assumption of factor immobility (for further discussion, see the conclusion). 
demand for local goods.

We find a closed form solution for the equilibrium distribution of firms and therefore for the degree of specialization. Such degree of specialization depends positively on the comparative advantage and on the returns to scale, and negatively on the trade costs.

A large productivity gap for the same sector across different locations, coupled with low trade costs and low elasticity of substitution, can generate full specialization as in a standard Ricardian model. Trade will be only interindustry, and slight changes in parameter values will have no effect on location and trade pattern.

For larger trade costs, smaller comparative advantage, and more modest returns to scale, each location is relatively specialized in the good in which it is more productive. As both regions accommodate both productions, there will be both intra-industry and inter-industry trade. Slight changes in parameter values will affect both location of production, the degree of specialization, and the composition of trade.

We adopted special assumptions to maintain the framework simple. Allowing for different sizes of the two locations would introduce market-size effects: by enjoying a lower price index and a higher real wage, the large location would be more attractive both for workers and for firms of both sectors. A generic comparative advantage would eliminate the mirror-image equilibrium production structure and would also generate market size effects, which would render more attractive the region with higher average productivity. Factor mobility across locations would make our equilibrium unstable, as it would unfasten the circular chain of concentration typical of the core-periphery model 〈K rugman [1991]〉; in the absence of centrifugal forces, such a process would lead to the concentration of the whole industrial activity (and not just of one sector) in one location.

\section{Appendix}

Proposition I: Under our assumptions all individuals receive the same wage even with inter-regional labor immobility and a comparative advantage.

Proof: We discuss the two possible equilibria separately. In an equilibrium 
with full specialization, all workers within one region will receive automatically the same wage. Equal share of expenditure on each good and equal labor endowment in the two regions ensure that the wage is the same in the two regions.

In an equilibrium where each region produces both goods, firms producing the same good in different locations must have the same sales. M oreover, they must pay the same wage, because by virtue of monopolistic competition under fixed costs and constant marginal costs, labor demand is independent of labor productivity, and sales are equal to factor rewards. Both the equal share of expenditure on the two goods and the intersectoral labor mobility ensures then that workers in different sectors have the same wage.

Proposition II: Wage cannot differ across regions in equilibrium (i.e., no other equilibrium -than the one shown in the paper- exists).

Proof: Let us consider any of the described equilibria and analyze the consequences of region 1 having a higher wage than region 2. Given markup pricing, optimal prices and sales of all firms located in region 1 will be relatively higher with respect to those of firms in region 2 . F or an equilibrium to occur, expenditure on all varieties produced in location 1 must also be relatively higher by the same proportion. However, the substitution effect would map this relative price change into lower sales for location l's variety and higher sales for location 2's variety. This completes the proof.

\section{References}

Davis D.R. [1995], "Intra-industry Trade: A Heckscher-O hlin-Ricardo Approach", Journal of International Economics, vol.39.

Dixit A. and Stiglitz J. E. [1977], "M onopolistic Competition and Optimum Product Diversity," American E conomic Review, vol. 67.

Helpman E. [1987], "Imperfect Competition and International Trade: Evidence from F ourteen Industrial Countries," Journal of the Japanese and International Economies, Vol. 1.

Helpman E. and Krugman P. [1985], Market Structure and Foreign Trade, 
Cambridge, M IT Press.

Krugman P. [1991], Geography and Trade, Cambridge, MIT Press.

Krugman P. [1990], Rethinking International Trade, Cambridge, M IT Press.

Krugman P. [1980], "Scale Economies, Product Differentiation, and the Pattern of Trade," American Economic Review, Vol. 70.

Krugman P and Obstfeld M. [1991], International Economics: Theory and Policy, N ew York, HarperCollins Publishers.

Krugman P. and Venables A. [1996], "Integration, Specialization, and Adjustment," European E conomic Review, Vol. 40.

M artin and Rogers [1995], "Industrial Location and Public Infrastructure," Journal of International Economics, Vol. 39.

Ruffin Roy [1988], "The M issing Link: The Ricardian Approach to the Factor Endowment Theory," American E conomic Review, Vol. 78.

Woodland A. D. [1989], Internati onal Trade and Resource Allocation, Amsterdam, North-Holland. 